\title{
Steriles Abwaschen bei Intimpiercing
}

\author{
Wie der Stichkanal eines Intimpiercings optimal desinfiziert und ein Verkleben verhindert \\ werden kann, erläutert unser Autor in folgendem Tipp.
}

Bei genitalen Operationen bestehen auch bei passager entnommenem Intimpiercing 2 Probleme: Zum einen kann der epithelialisierte Stichkanal nur unzureichend desinfiziert werden, zum anderen besteht häufig die Befürchtung der Betroffenen, dass der Kanal vor allem bei relativ frischen Piercings - dem Stichkanal eines suprapubischen Katheters nicht unähnlich - verkleben kann und eine Neuanlage erforderlich wird.

Wir gehen so vor: Nach Entnahme des Piercings unmittelbar vor der Operation durch den Patient wird wie gewohnt abgewaschen und dabei der bestehende Hautkanal mehrfach durchtränkt. Dann wird nach Aufbringen der Abdeckung mit separatem Instrumentarium ein Silikonzügel als Platzhalter eingeführt und über der Haut verknotet. Nach Handschuhwechsel deckt eine Folie den Bereich ab und verhindert eine Keimverschleppung. Nach Verband der eigentlichen Wunde kann dann der Silikonzügel als Platzhalter so lange verbleiben, bis die Patientin/der Patient - wie im gezeigten Falle - den Intimschmuck wieder selbst einsetzen kann.

\section{PD Dr. Andreas Wiedemann}

Korrespondenz:

PD Dr. Andreas Wiedemann Urologische Klinik

Evangelisches Krankenhaus im Diakoniewerk Ruhr gGmbH

Lehrstuhl für Geriatrie

der Universität Witten/Herdecke

Pferdebachstr. 27

58455 Witten

Tel.: 02302/175-2521

awiedemann@diakonie-ruhr.de

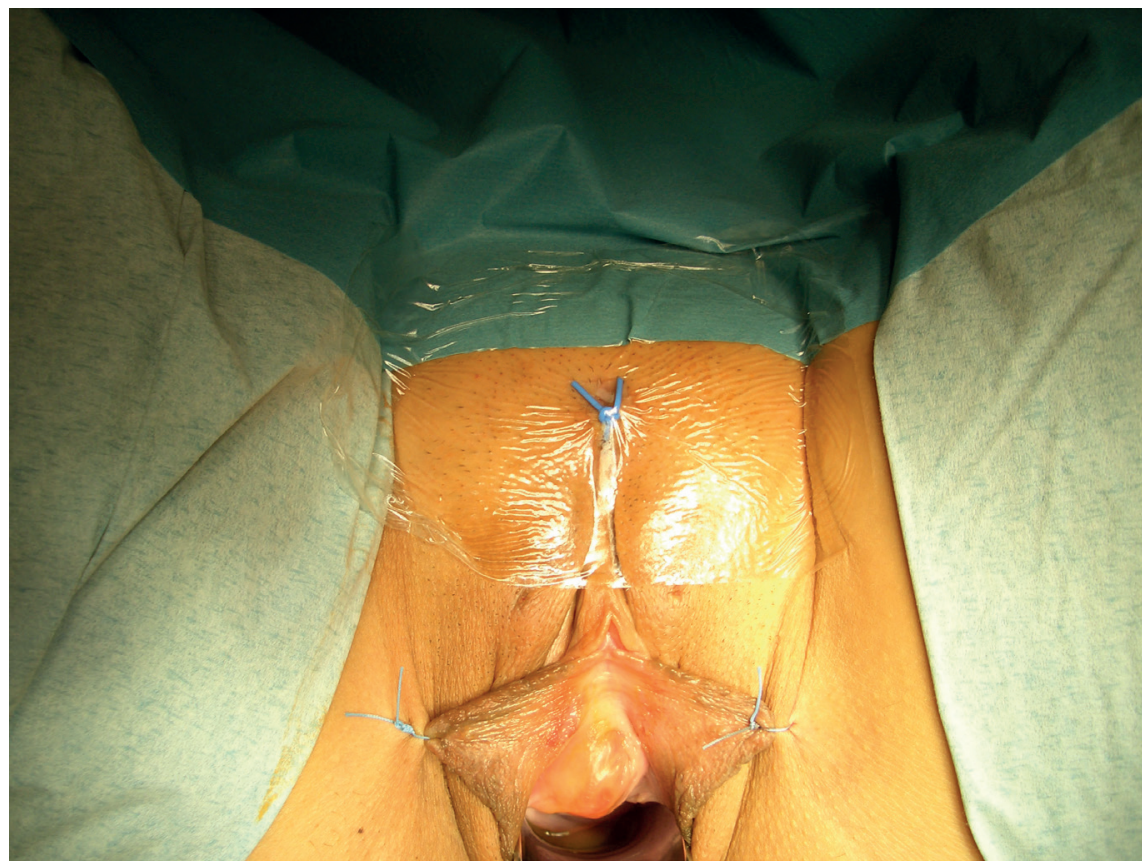

Ein steril eingebrachter Silikonzügel verbleibt als Platzhalter solange postoperativ, bis die Patientin den Intimschmuck wieder selbst einsetzen kann. Eine sterile Folie deckt den betroffenen Bereich zusätzlich ab (hier bei der Excision eines rechts paraurethral sichtbaren Harnröhrendivertikels). 